Article

\title{
Novel Biobased Polyol Using Corn Oil for Highly Flame-Retardant Polyurethane Foams
}

\author{
Sneha Ramanujam ${ }^{1}$, Camila Zequine ${ }^{1}$, Sanket Bhoyate ${ }^{1}$, Brooks Neria ${ }^{1}$, Pawan K. Kahol ${ }^{2}$ and \\ Ram K. Gupta ${ }^{1, *}$ \\ 1 Department of Chemistry, Pittsburg State University, Pittsburg, KS 66762, USA; \\ sramanujam@gus.pittstate.edu (S.R.); camilazequine@hotmail.com (C.Z.); \\ sanketbhoyate931@gmail.com (S.B.); bneria@pittstate.edu (B.N.) \\ 2 Department of Physics, Pittsburg State University, Pittsburg, KS 66762, USA; pkahol@pittstate.edu \\ * Correspondence: rgupta@pittstate.edu; Tel.: +1-620-235-4763; Fax: +1-620-235-4003
}

Received: 31 January 2019; Accepted: 11 March 2019; Published: 14 March 2019

\begin{abstract}
A novel bio-based polyol was synthesized using corn oil and 2-mercaptoethanol via thiol-ene reaction as an alternative to petroleum-based polyol for the synthesis of polyurethane foams. The polyol was analyzed using wet chemical techniques to obtain hydroxyl number and viscosity. Infrared spectroscopy and gel permeation chromatography were used to confirm the structural properties of the foams. Flame-retardant polyurethane foams were prepared by the addition of different concentrations of dimethyl methyl phosphonate (DMMP) in final foam composition. The effect of DMMP on the thermo-mechanical properties of the polyurethane foams was analyzed. The TGA analysis showed improved stability of the final char with addition of DMMP in the foams. All the foams maintained a well-defined cellular structure and over $95 \%$ of closed cell content. The horizontal burning test showed reduced burning time and weight loss from $115 \mathrm{~s}$ and $38 \mathrm{wt} . \%$ for the neat foams, to $3.5 \mathrm{~s}$ and $5.5 \mathrm{wt} . \%$ for DMMP-containing foams (1.94 wt.\% P). The combustion test using cone calorimeter showed a considerable reduction in heat release rate and total heat release. Thus, our study shows that corn-oil based polyol can be used to produce renewable polyol for industrially producible rigid polyurethane foams. The addition of a small amount of DMMP could result in a significant reduction in the flame-retardant properties of the polyurethane foams.
\end{abstract}

Keywords: biobased polyol; thiol-ene chemistry; flame-retardant polyurethane foams; thermal insulation

\section{Introduction}

Polyurethane foams have been widely studied due to a versatile range of properties, such as low thermal conductivity, electrical insulation properties, low density, higher mechanical strength, and chemical resistance, making them suitable for various applications [1-4]. The mechanical and physical properties of the polyurethane foam depend upon the type of polyol used during its synthesis [3]. Majority of the starting materials used for synthesizing polyurethane foams are derived from petroleum-based resources. Due to rising environmental concerns, the use of renewable materials for synthesizing polyurethane foams could reduce the burden on petroleum resources [5]. Several bio-based materials such as soybean oil, orange oil, castor oil, sunflower oil, cardanol oil, and starch have been used as starting materials for the preparation of polyurethane foams [5-12]. The United States Department of Agriculture estimates that corn production will reach 371.52 million metric tonnes in 2019. $[13,14]$. As compared to other vegetable oils, corn oil has a competitive price range ( $26.5-30.5$ cents $/ \mathrm{lb})$ and could serve as a promising candidate for synthesizing of bio-based polyurethane foams [14]. Majority of vegetable oils consist of polyunsaturated fatty acids that allow 
the possibility of simple chemical modifications to create hydroxyl groups $[3,8,15,16]$. Similarly, chemical modification of corn oil can result in polyols to develop renewable, low cost, and industrially producible foams.

The chemical constituents of polyurethane foams majorly consist of oxygen, carbon, and hydrogen, which makes them susceptible to fire $[17,18]$. Moreover, low density and ease in air permeability allow for a higher fire growth velocity [17]. In order to counter this issue, compounds such as additive and reactive flame retardants consisting of halogenated and non-halogenated compounds or, inorganic metal oxides, and hydroxides are added within the foam matrix during the synthesis $[8,19,20]$. Reactive flame retardants consist of compounds with functional groups that can readily get bonded within the foam matrix $[6,8,9,21]$. In practice, separate synthesis for such flame retardants could add to the cost of the final foams, while additive flame retardants consist of simple compounds and require very little concentrations to impart flame retardancy [7]. Although halogenated flame retardants are widely used, they suffer from several environmental issues $[20,22,23]$. Phosphorus-containing flame retardants serve as promising candidates to counter this issue. In our previous studies, we observed that the addition of a small concentration of dimethyl methyl phosphonate (DMMP) showed a significant reduction in self-extinguishing time of the fire $[7,10]$. During a fire test, phosphorus compound created a protective char over the surface of the foam, preventing fire growth. Hence, the addition of DMMP within the foam matrix could provide flame-retardant properties.

In this work, unmodified corn oil was used for the synthesis of novel polyol using one-step, solvent free, and cost-effective thiol-ene chemistry. The flame retardancy of polyurethane foams was improved using DMMP. The effect of different concentrations of DMMP addition on the physicomechanical and thermal property of the polyurethane foams was studied in detail. It was observed that the addition of a low concentration of DMMP in foams showed significant reduction in self-extinguishing time, heat release rate, and total heat release.

\section{Materials and Methods}

\subsection{Materials}

Mazola corn oil (96 oz. plastic canister) was purchased from the local Walmart, (Pittsburg, KS, USA). 2-Mercaptoethanol was purchased from Acros Organic, PA, USA. Jeffol SG-360 and Rubinate M isocyanate (methylene diphenyl diisocyanate, NCO content of 31\%) were purchased from Huntsman, Texas, USA. DABCO T-12 was received from Air Products, USA and NIAX A-1 was received from OSi Specialties, CT, USA. Silicone-based surfactant (Tegostab B-8404) was purchased from Evonik, USA. Distilled water was used as a blowing agent. Dimethyl methyl phosphonate (DMMP) and 2-hydroxy-2-methyl propiophenone were purchased from Sigma-Aldrich, St. Louis, MO, USA.

\subsection{Synthesis of Corn Oil-Based Polyol}

Corn oil-based polyol was synthesized via thiol-ene reaction using UV irradiation. The corn oil (CO) (200 g) and 2-mercaptoethanol (ME) (149 g) were added in a molar ratio of 1:4 along with $2.5 \mathrm{wt} . \%$ of a photoinitiator (2-hydroxy-2-methyl propiophenone). The unsaturation level in the corn oil was determined using iodine value and the corresponding amount of 2-mercaptoethanol was used. The reaction was carried out at room temperature under continuous stirring for $6 \mathrm{~h}$ and UV radiation intensity of $365 \mathrm{~nm}$. The reaction for the synthesis of corn oil-based polyol for polyurethanes is given in Figure 1. 


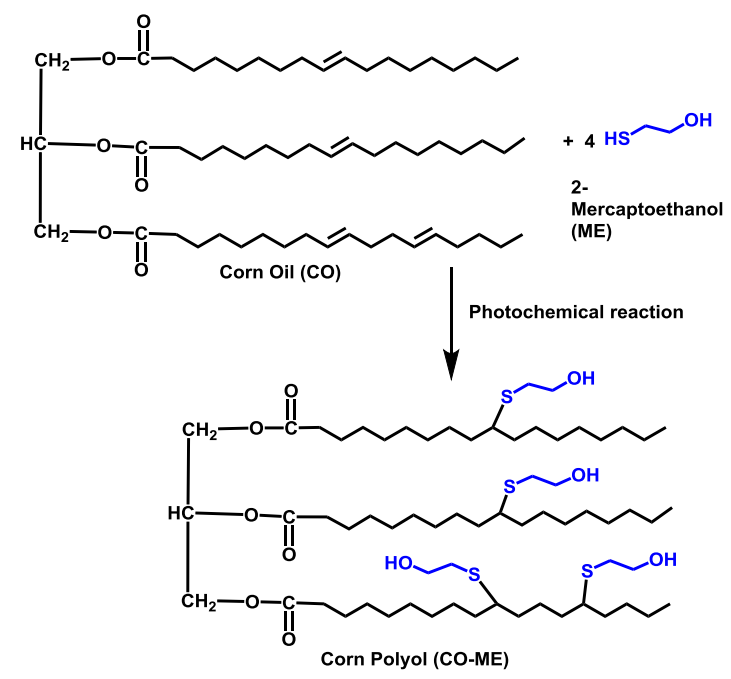

Figure 1. Synthesis of the corn oil-based polyol.

\subsection{Characterization of Polyol}

The synthesized corn oil-based polyol was analyzed using the standard wet characterization technique. The hydroxyl number (OH number) of the polyols was determined by the phthalic anhydride/pyridine (PAP) method, according to American Society for Testing and Materials (ASTM $\mathrm{D}$ 4274). The acid value was determined according to IUPAC 2.201 standard using the indicator method. Iodine value of the corn oil and polyol was determined using the Hanus method. The corn oil and polyol was treated with excess of the Hanus solution (BrI) and unreacted BrI was reacted with potassium iodide to form iodine. The iodine concentration was determined by titration with sodium thiosulfate. The viscosity of the polyol was measured using an AR 2000 dynamic stress rheometer (TA Instruments, New Castle, DE, USA) at $25{ }^{\circ} \mathrm{C}$ with a linear increase in shear stress from 1 Pa to $2000 \mathrm{~Pa}$. The rheometer consists of a cone plate with a cone diameter of $25 \mathrm{~mm}$ and angle between $2^{\circ}$. The FT-IR spectrum of the polyol was obtained using Shimadzu IR Affinity-1 spectrophotometer (Columbia, MD, USA) at room temperature. The molecular weight of the polyols was analyzed using gel permeation chromatography (GPC) using a system by Waters (Milford, MA, USA). The system consists of four $300 \times 7.8 \mathrm{~mm}$ phenogel $5 \mu$ columns with different pore sizes of 50, 102, 103 and $104 \AA$. The eluent solvent was tetrahydrofuran and the eluent rate was maintained at $1 \mathrm{ml} / \mathrm{min}$ at $30{ }^{\circ} \mathrm{C}$. A Bruker DPX-300 spectrometer (Billerica, MA, USA) was used to acquire the ${ }^{1} \mathrm{H}$ and ${ }^{13} \mathrm{C}$ nuclear magnetic resonance spectra. Deuterated chloroform $\mathrm{CDCl}_{3}$ was used as a solvent and tetramethyl silane as internal reference. The experiments were carried out at $300 \mathrm{MHz}$ and eight scans for proton NMR at room temperature.

\subsection{Preparation of Flame Retardant Rigid Polyurethane Foam}

The structure of methylene diphenyl diisocyanate (MDI) and DMMP is given in Figure 2. The composition of the polyurethane foams consists of a different concentration of phosphorous as given in Table 1. Except for MDI, all the ingredients were added into a 500-mL cup and stirred vigorously (3000 rpm) to form a homogeneous mixture. After complete mixing, $26.20 \mathrm{~g}$ of MDI was added into the mixture and stirred at $3000 \mathrm{rpm}$ to make polyurethane foams. The obtained foams were designated as P-0 wt.\%, P-0.26 wt.\%, P-0.51 wt.\%, P-1 wt.\%, P-1.5 wt.\%, P-1.9 wt.\% and P-2.4 wt.\%, respective to the percentage of phosphorous added. Some of the important industrial characteristics such as mix time, cream time, rise time and tack-free time was measured using the ASTM D7487 standard (see Table 2). 


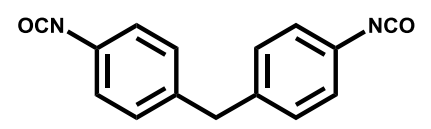

(a)

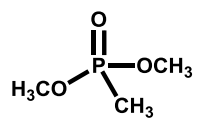

(b)

Figure 2. Structure of MDI (a) and DMMP (b).

Table 1. Formulation for preparation of phosphorus-containing polyurethane foams.

\begin{tabular}{cccccccc}
\hline Compounds & $\begin{array}{c}\text { P-0 } \\
\text { wt. } \%\end{array}$ & $\begin{array}{c}\text { P-0.26 } \\
\text { wt. } \%\end{array}$ & $\begin{array}{c}\text { P-0.51 } \\
\text { wt.\% }\end{array}$ & $\begin{array}{c}\text { P-1 } \\
\text { wt. } \%\end{array}$ & $\begin{array}{c}\text { P-1.5 } \\
\text { wt. } \%\end{array}$ & $\begin{array}{c}\text { P-1.9 } \\
\text { wt.\% }\end{array}$ & $\begin{array}{c}\text { P-2.4 } \\
\text { wt. } \%\end{array}$ \\
\hline Jeffol-360 & 10.00 & 10.00 & 10.00 & 10.00 & 10.00 & 10.00 & 10.00 \\
CO-ME & 10.00 & 10.00 & 10.00 & 10.00 & 10.00 & 10.00 & 10.00 \\
DMMP & 0 & 0.50 & 1.00 & 2.00 & 3.00 & 4.00 & 3.00 \\
Tegostab B-8404 & 0.40 & 0.40 & 0.40 & 0.40 & 0.40 & 0.40 & 0.40 \\
Niax-A1 & 0.14 & 0.14 & 0.14 & 0.14 & 0.14 & 0.14 & 0.14 \\
T-12 & 0.04 & 0.04 & 0.04 & 0.04 & 0.04 & 0.04 & 0.04 \\
Water & 0.80 & 0.80 & 0.80 & 0.80 & 0.80 & 0.80 & 0.80 \\
MDI & 26.20 & 26.20 & 26.20 & 26.20 & 26.20 & 26.20 & 26.20 \\
\hline
\end{tabular}

All the weights are in grams.

Table 2. Some of the processing time characteristics of the polyurethane foams.

\begin{tabular}{cccccccc}
\hline Characteristics & $\begin{array}{c}\text { P-0 } \\
\text { wt.\% }\end{array}$ & $\begin{array}{c}\text { P-0.26 } \\
\text { wt. } \%\end{array}$ & $\begin{array}{c}\text { P-0.51 } \\
\text { wt. } \%\end{array}$ & $\begin{array}{c}\text { P-1 } \\
\text { wt. } \%\end{array}$ & $\begin{array}{c}\text { P-1.5 } \\
\text { wt. } \%\end{array}$ & $\begin{array}{c}\text { P-1.9 } \\
\text { wt.\% }\end{array}$ & $\begin{array}{c}\text { P-2.4 } \\
\text { wt.\% }\end{array}$ \\
\hline Mix time & 7 & 6 & 7 & 6 & 6 & 7 & 7 \\
Cream time & 6 & 6 & 6 & 7 & 6 & 6 & 7 \\
Rise time & 12 & 11 & 12 & 12 & 11 & 12 & 11 \\
Tack free time & 16 & 16 & 15 & 16 & 15 & 16 & 16 \\
\hline
\end{tabular}

All the time is in seconds.

\subsection{Characterization of Polyurethane Foams}

At first, the foam samples were cut in a cylindrical shape of $45 \mathrm{~mm} \times 30 \mathrm{~mm}$ (diameter $\times$ height) for further characterization. The samples were used to analyze the apparent density and closed-cell content. The apparent density of the foams was measured according to ASTM D 1622. The closed-cell content of the foams was measured using a Ultrapycnometer (Ultrafoam 1000) according to ASTM D 285. For the compression test, the foam samples were cut in dimensions of $50 \mathrm{~mm} \times 50 \mathrm{~mm} \times 25 \mathrm{~mm}$ (length $\times$ width $\times$ height). The compressive strength at $10 \%$ strain was determined by using a Q-Test 2-tensile machine (MTS, Raleigh, NC, USA) according to ASTM D 1621. The compressive force was applied at the strain rate of $30 \mathrm{~mm} / \mathrm{min}$, parallel to the direction of the foam. The microstructure and cell size distribution of the rigid polyurethane foams were studied using a Phenom G2 Pro scanning electron microscope (SEM) (Phenom, Netherlands). Before imaging, all the foam samples were gold sputtered to avoid a charging effect during imaging. Thermogravimeric analysis (TGA) was performed using TA instrument (TGA Q500, New Castle, DE, USA) to analyze the thermal behavior of the foams. The thermogravimetric analysis was performed under a nitrogen atmosphere by heating the foams from room temperature to $600{ }^{\circ} \mathrm{C}$ at $10^{\circ} \mathrm{C} / \mathrm{min}$. TGA was also performed under air for some samples for comparison. Fire-retardant properties were studied using the horizontal burning test (ASTM D 4986-98). After exposing specimens (sized at $150 \mathrm{~mm} \times 50 \mathrm{~mm} \times 12.5 \mathrm{~mm}$ ) to the flame for $10 \mathrm{~s}$, burning time and weight difference (before and after the burn) were recorded. For the cone calorimeter tests, the test specimens were cut into a size of $100 \mathrm{~mm} \times 100 \mathrm{~mm} \times 25 \mathrm{~mm}$ (length $\times$ width $\times$ height) according to ISO 5560 standard and exposed to the external heat flux of $35 \mathrm{~kW} / \mathrm{m}^{2}$ using a standard cone calorimeter (Fire Testing Technology). The total heat release and heat release rate of the samples were analyzed. 


\section{Results and Discussion}

\subsection{Properties of Polyol}

The synthesized corn oil-based polyol (CO-ME) showed a hydroxyl number and an acid value of $176 \mathrm{mg} \mathrm{KOH} / \mathrm{g}$ and $1.77 \mathrm{mg} \mathrm{KOH} / \mathrm{g}$, respectively, with about 99\% yield. The percentage yield was calculated by measuring the iodine value of corn oil and polyol [\% yield = (Iodine value of polyol/iodine value of corn oil) $\times 100 \%]$. Since the hydroxyl group acts as a main reactive group with isocyanate, the hydroxyl number provides an insight of reactivity of the polyol. On the other hand, the acid value corresponds to the number of acid groups in oligo-polyol [24]. The reaction of polyurethanes is catalyzed by ternary amines; hence, low acid value suggests a higher degree of reactivity during the foaming process and appropriate catalytic activity without acid-base neutralizing side reactions. The functionality and molecular weight of the synthesized bio-polyol was determined to be 3.7 and $1182 \mathrm{~g} / \mathrm{mol}$, respectively [24]. The lower viscosity of the polyol (1.33 Pa.s) results in homogeneous mixing and allows improved ease in processing. The structural characteristics of the synthesized polyol were studied using FT-IR spectra. Figure 3a shows the FT-IR spectrum of the raw materials and the final polyol. The peak intensity around $3432 \mathrm{~cm}^{-1}$ in the polyol suggests the presence of hydroxyl groups $(-\mathrm{OH})$. The peak around $2551 \mathrm{~cm}^{-1}$ is the characteristic peak of S-H stretching of 2-mercaptoethanol. The disappearance of this peak in the FT-IR spectrum of the polyol suggests that the reaction has been carried out. All the FT-IR spectrum peaks were close to the previous studies $[7,25]$. The gel permeation chromatography graph shows a change in the molecular weight of the reacting species as the reaction proceeds and final polyol is obtained. It can be clearly observed in Figure $3 b$ that the retention time for final polyol decreased to around $30 \mathrm{~min}$ as compared to pure $\mathrm{CO}$ (33 min) and ME (40.5 min). Peak around $32 \mathrm{~min}$ within the final polyol could be due to less reactivity of the inner double bonds within the structure of the corn oil [9]. The disappearance of retention peak for $\mathrm{ME}$ in the final polyol suggests purity of the final polyol. The synthesized polyol was further characterized using proton and carbon NMR. The disappearance of the signal around $5.4 \mathrm{ppm}$ corresponding to $=\mathrm{C}-\mathrm{H}$ confirms the attachment of the thiol group to the double bond. ${ }^{13} \mathrm{C}$ NMR of corn oil and polyol is shown in Figure 3c. Corn oil shows a signal around 128 ppm which corresponds to $\mathrm{C}=\mathrm{C}$. The disappearance of this peak in polyol confirms the thio-ene reaction.
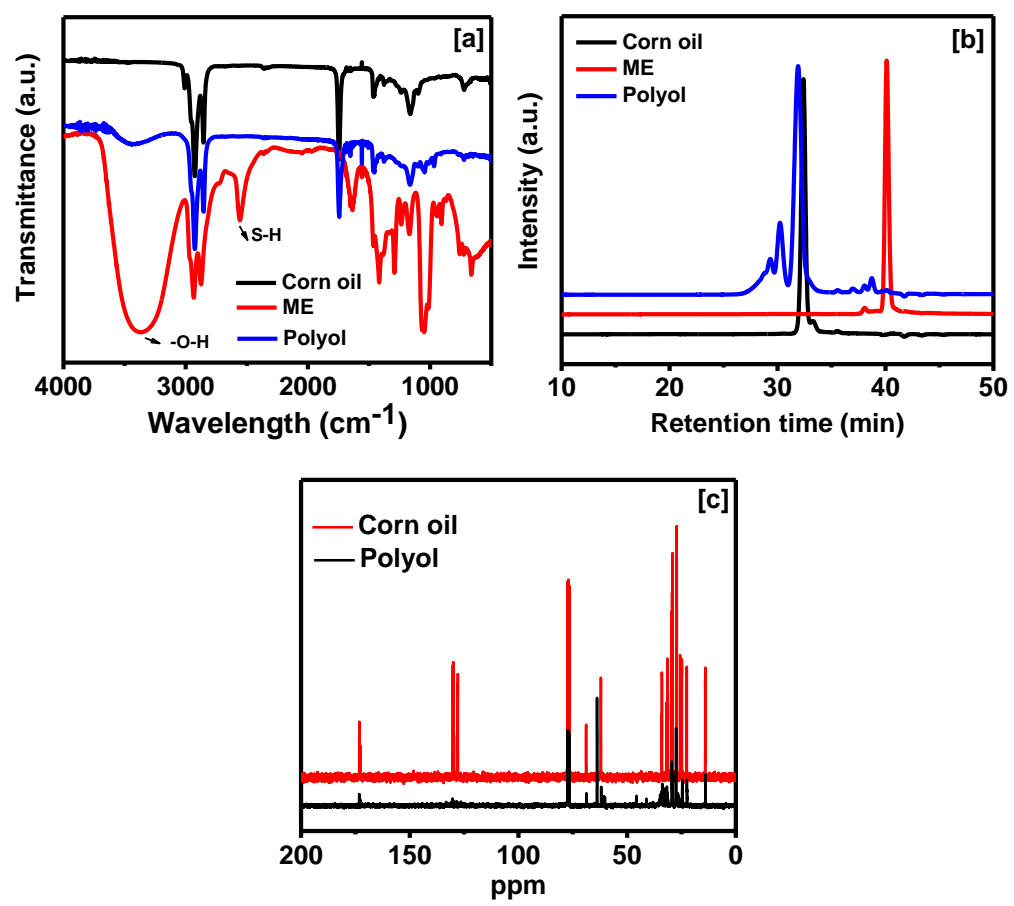

Figure 3. (a) FT-IR; (b) GPC graphs and (c) ${ }^{13} \mathrm{C}$ NMR for the starting materials and their polyol. 


\subsection{Properties of Corn Oil-Based Polyurethane Foams}

The optical images of the synthesized foams can be observed in Figure 4. All the foams showed uniform growth and well-defined structure suitable for industrial applications.
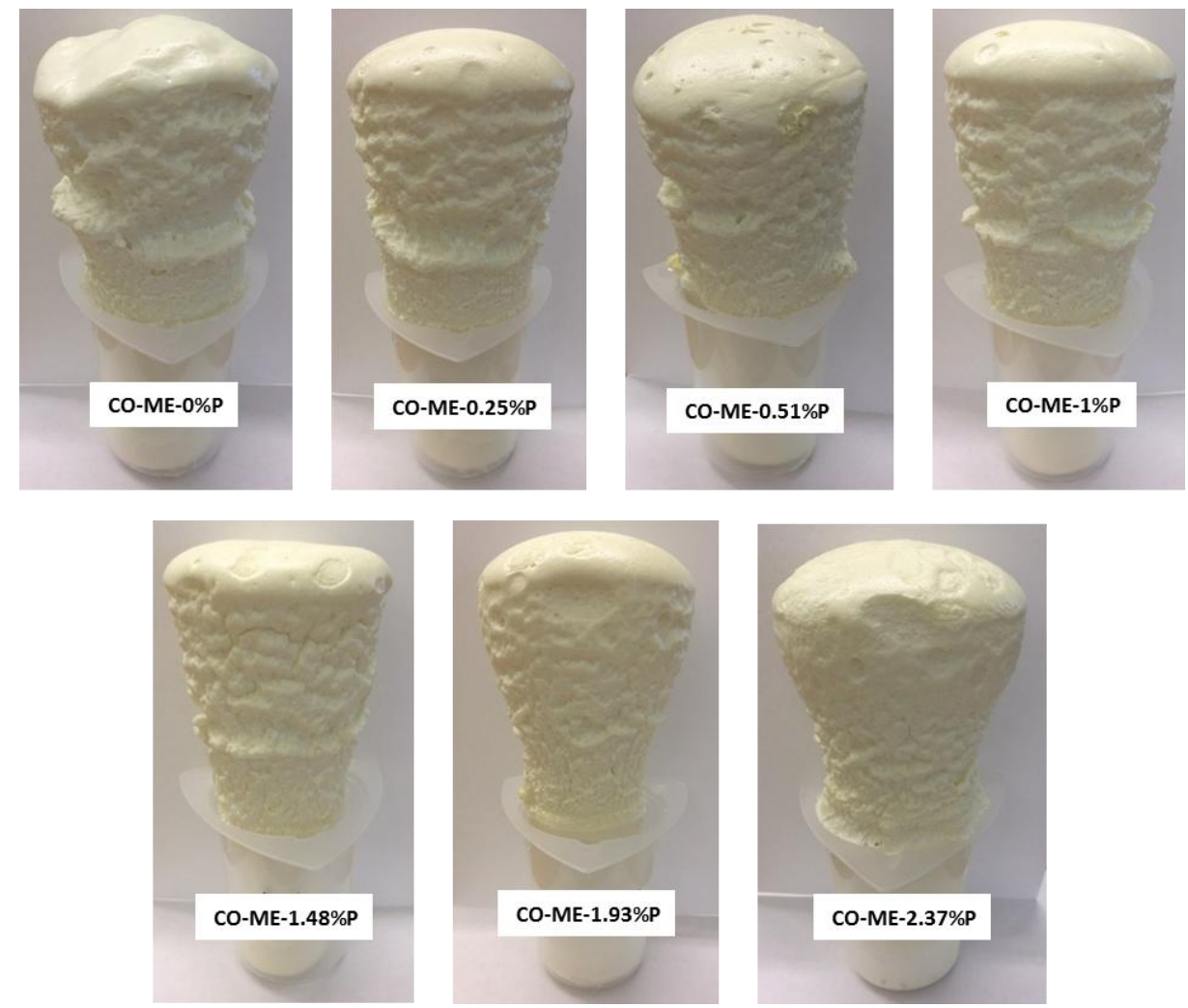

Figure 4. Photographs of the prepared polyurethane foams with various concentration of DMMP as a flame-retardant additive.

The apparent density of the polyurethane foams is an important parameter to determine its physical and mechanical properties. The average apparent density was calculated from cylindrical and square-shaped test specimens, as shown in Figure 5a. All the foams showed an apparent density of $35 \mathrm{~kg} / \mathrm{m}^{3}$ with appropriate weight standards. [26] The addition of DMMP showed no significant change in the apparent density of the foams. In Figure 5b, it can be observed that the percentage of closed cell content of all the synthesized polyurethane foams was above $95 \%$. The closed cell structure of the foam supports the thermal insulation properties of the polyurethane foams [7]. Higher closed cell content prevents rapid heat transfer between the cells (as air acts as an insulator) and prevents an easy access pathway for oxygen during combustion [8,9]. To understand the effect of the addition of DMMP on the mechanical properties of the foams, a compression strength study was performed for all the foams containing a different concentration of phosphorus (Figure $5 \mathrm{c}$ ). As the concentration of DMMP increases, the compression properties of the foams decrease. Foams without DMMP showed compressive strength of $\sim 120 \mathrm{kPa}$, which reduced to $81 \mathrm{kPa}$ after addition of DMMP $(0.5 \mathrm{wt} . \% \mathrm{P})$. This could be due to the plasticizing effect of DMMP, resulting in increased cellular size and decrease in compressive properties. The low values of compression strength can also be due to the presence of vegetable oil-based polyol consisting of flexible tri-glyceride chains and moderate $\mathrm{OH}$ number. [6]

Figure 6 shows the SEM images of all the foams with different concentrations of DMMP. Foams without DMMP showed an average cell size of $250 \mu \mathrm{m}$ with uniform circular shape. As the concentration of DMMP increases, a slight increase in cell size was observed and comparable to previous reports $[7,10]$. Although the addition of DMMP showed little distortion in the circular shape of the foams, all the foams maintain promising physicomechanical properties. 

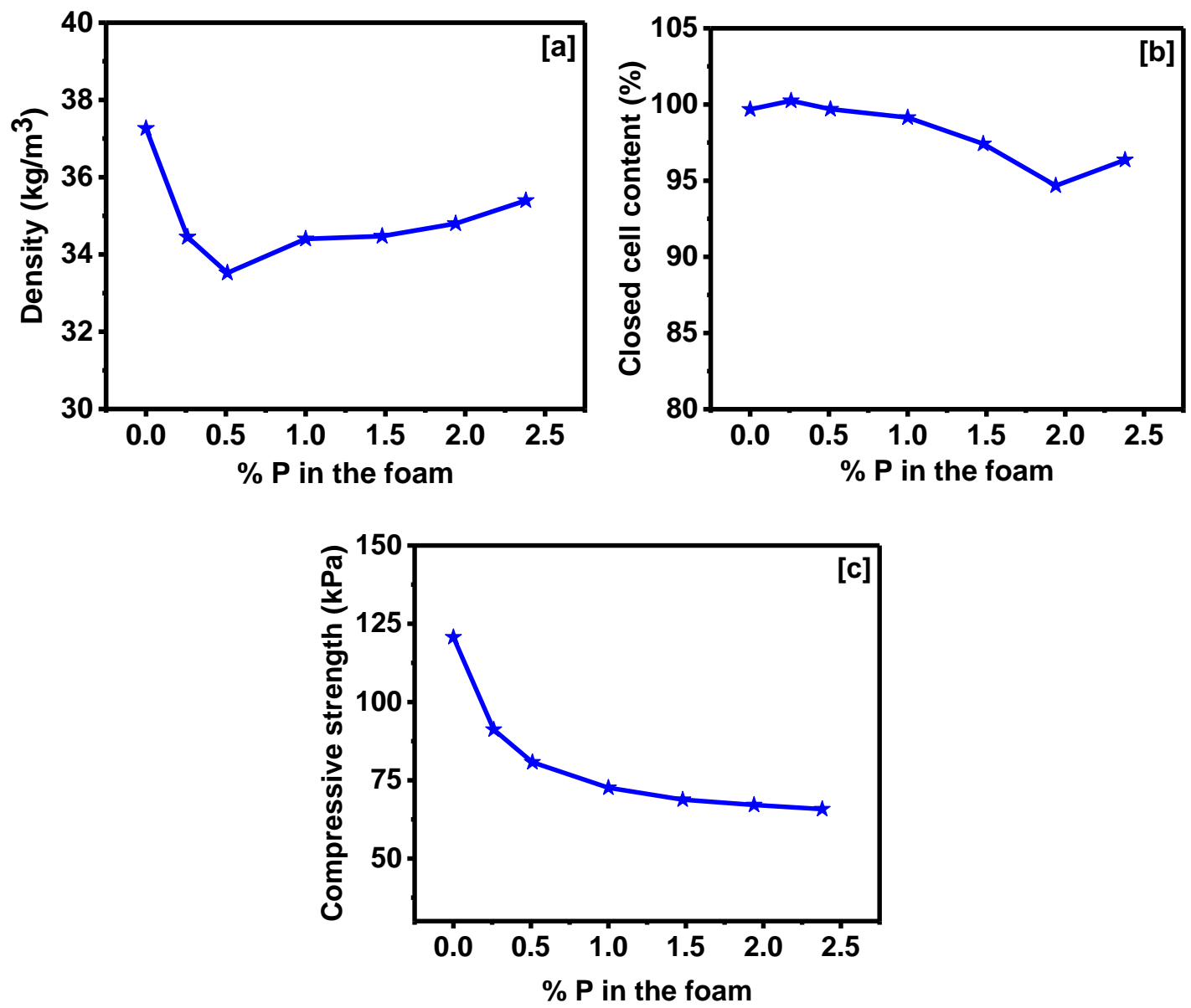

Figure 5. (a) Apparent density; (b) closed cell content; and (c) compression strength for corn oil-based polyurethane foams.
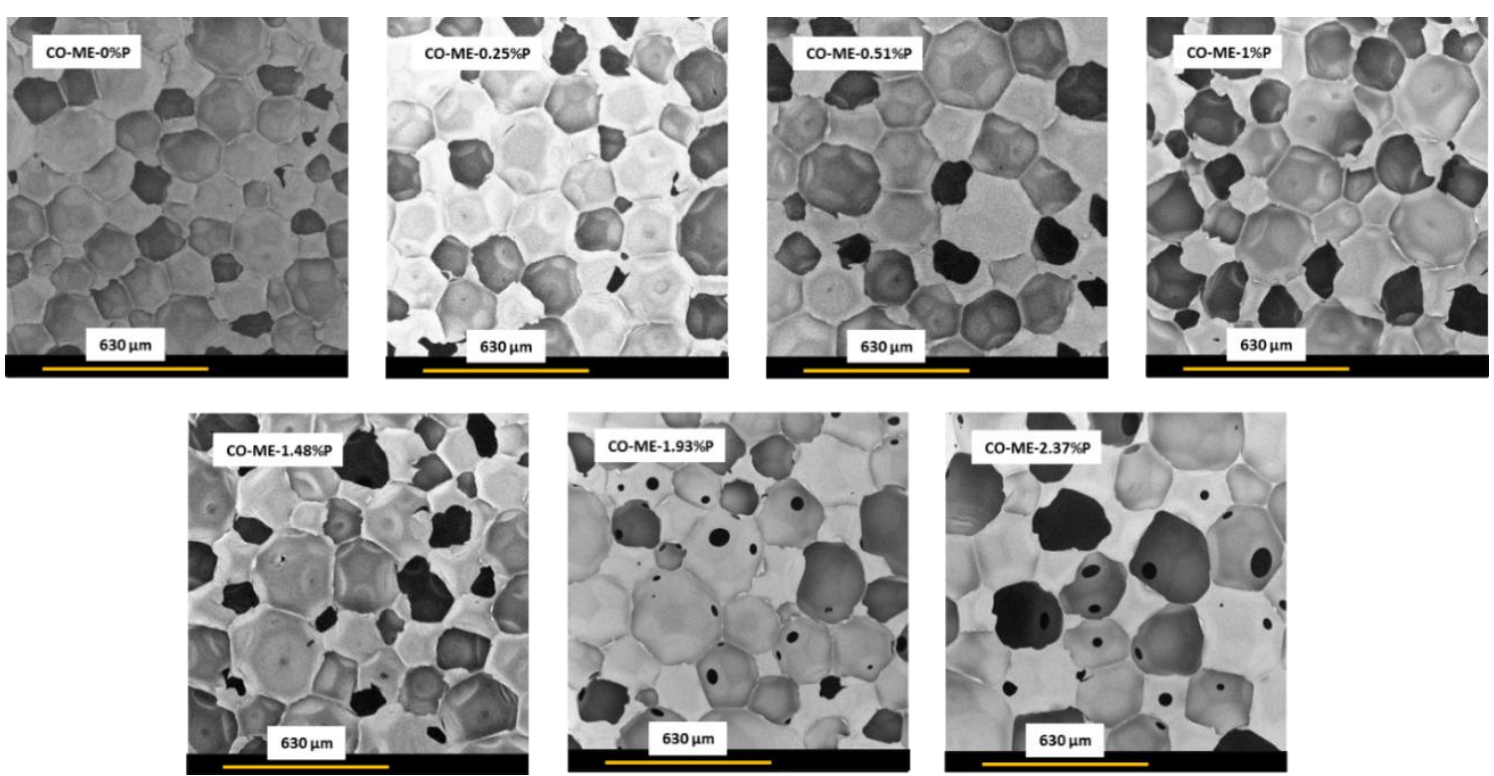

Figure 6. SEM images of the polyurethane foams containing various amounts of DMMP.

The thermal stability of polyurethane foams was studied using thermogravimetric analyses (TGA) in a nitrogen environment. Polyurethane foams without DMMP showed three transitions around 325,360 and $475{ }^{\circ} \mathrm{C}$, corresponding to the decomposition of the main chain, pyrolysis of polyol 
and isocyanate, and degradation of char layer [6,27] (see Figure 7a). However, with the addition of DMMP, an extra transition was observed around $100-150{ }^{\circ} \mathrm{C}$, corresponding to the volatilization of DMMP [10]. This peak increases with DMMP concentration resulting in improved char stability observed in later decomposition peak around $360^{\circ} \mathrm{C}$ and $475^{\circ} \mathrm{C}$ [28-30]. The volatilization of DMMP results in decomposition of a less-stable $-\mathrm{P}-\mathrm{O}-\mathrm{C}-$ bond, which further assists in the formation of a char layer that inhibits fire [31]. Figure 7a shows improvement in the final char content of the foams as the amount of DMMP was raised, suggesting the formation of stable char that could act as a barrier to improve flame retardancy. This could be correlated with improved flame retardancy observed in the horizontal burning test and the combustion test discussed later. The thermal behavior of two samples containing $0.51 \%$ and $1.9 \%$ of phosphorous was compared in nitrogen and air atmosphere. As is seen in Figure $7 \mathrm{~b}$, the thermal decomposition behavior in nitrogen and air atmosphere is similar, with little difference in residual content at high temperatures.
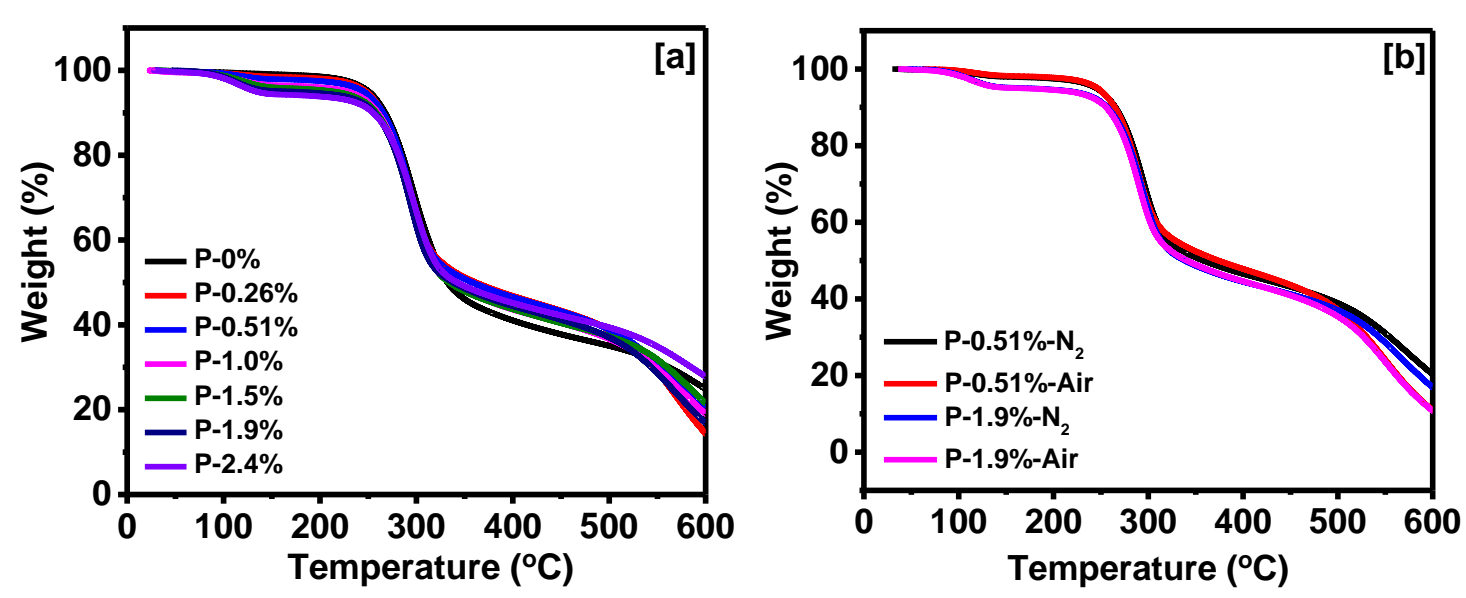

Figure 7. (a) TGA for polyurethane foams in a nitrogen environment and (b) TGA for polyurethane foams in nitrogen and air environment.

The flame-retardant properties of the foams were studied using a horizontal burning test as per ASTM D 4986-98. The foams were held horizontally and subjected to a continuous flame for $10 \mathrm{~s}$. Burning time, along with respective weight loss, was recorded, as shown in Figure 8 . The neat foams showed a burning time of $115 \mathrm{~s}$ and weight loss of $38 \mathrm{wt} . \%$, which significantly reduced to $3.5 \mathrm{~s}$ and $5.5 \mathrm{wt} . \%$ after addition of DMMP for $1.94 \mathrm{wt.} \%$ P foams. Ranaweera et al. synthesized rigid polyurethane foams using limonene polyol and studied flame retardant properties by the addition of different amounts of DMMP [10]. The foams containing $6 \mathrm{wt} . \%$ of DMMP showed the lowest burning time of $19 \mathrm{~s}$. Similarly, in our previous report, we observed that the $1.7 \mathrm{wt} . \% \mathrm{P}$ foams prepared using DMMP as a flame retardant showed burning time and weight loss of $\sim 5 \mathrm{~s}$ and $\sim 5 \mathrm{wt} . \%$, respectively [7]. Our study shows improved flame retardant properties, as compared to previous results. Figure 9 shows optical images of the burnt foams with different concentrations of phosphorus within the foams. The improved flame retardancy could be due to the two-way active contribution of DMMP, including condensed and vapor phase [7]. Firstly, the decomposition of DMMP could promote the formation of phosphoric acid resulting in pyrophosphate structure by dehydrating the polymer matrix containing oxygen (in this case due to polyol) [32]. Such dehydration further results in the formation of carbocation and a carbon-carbon double bond, which at higher temperatures forms a carbonized crosslinked structure, such as an intumescent barrier char layer over the surface of the foam preventing the combustible media, oxygen and thermal energy from propagating. Secondly, radical phosphorus species such as $\mathrm{PO}^{*}, \mathrm{PO}_{2}{ }^{*}$ and $\mathrm{OHPO}^{*}$ help in inhibition of $\mathrm{H}^{*}$ and $\mathrm{OH}^{*}$ [33]. Therefore, with the addition of a small amount of DMMP, efficient flame retardancy can be achieved.

The combustion test was performed using a cone calorimeter to study flame-retardant characteristics in detail. A control foam and foam containing $1.5 \mathrm{wt} . \%$ phosphorus were exposed to the 
flame test. Figure 10a,b shows the heat release rate (HRR) and total heat release (THR) behavior of the foams. Total heat release for the foam containing $1.5 \%$ phosphorous showed $21 \%$ reduction in THR, compared to the control foam. The protective char formed due to the addition of DMMP improves the flame retardancy for the foam and reduces the heat transfer to the underlying layer [34,35]. Hence, from the overall study, it can be concluded that the addition of DMMP within the foam matrix could improve the flame-retardant properties of the foams.
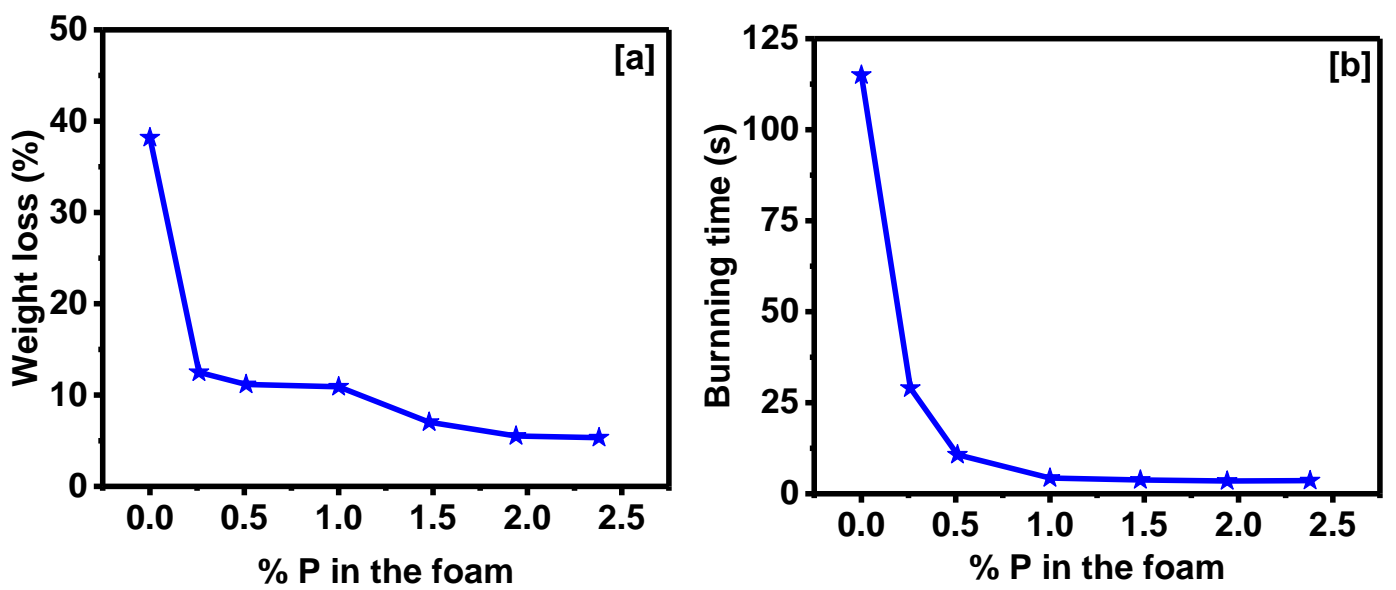

Figure 8. (a) Percentage weight loss after burning and (b) burning time for corn oil-based polyurethane foams.
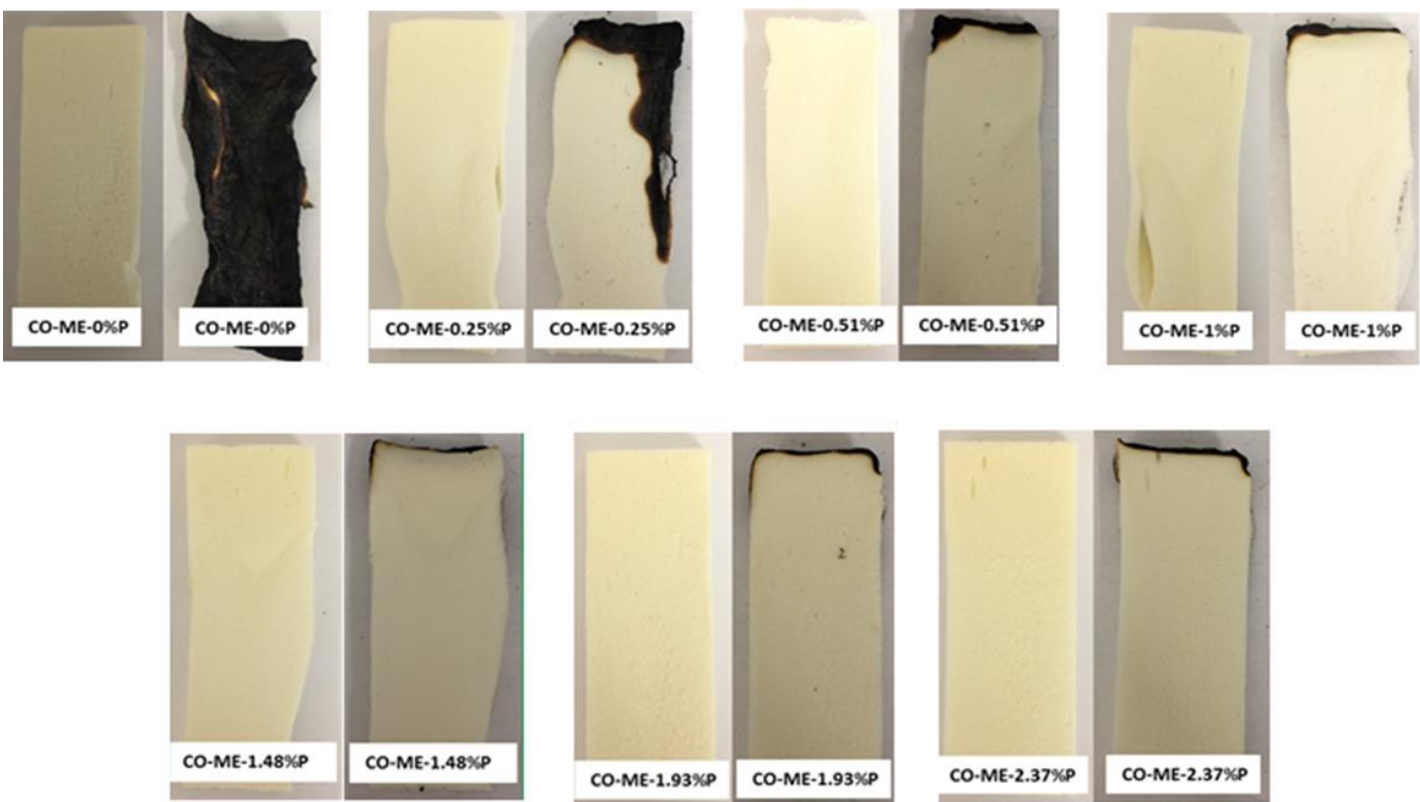

Figure 9. Photographs of the foams before and after the burning test. 

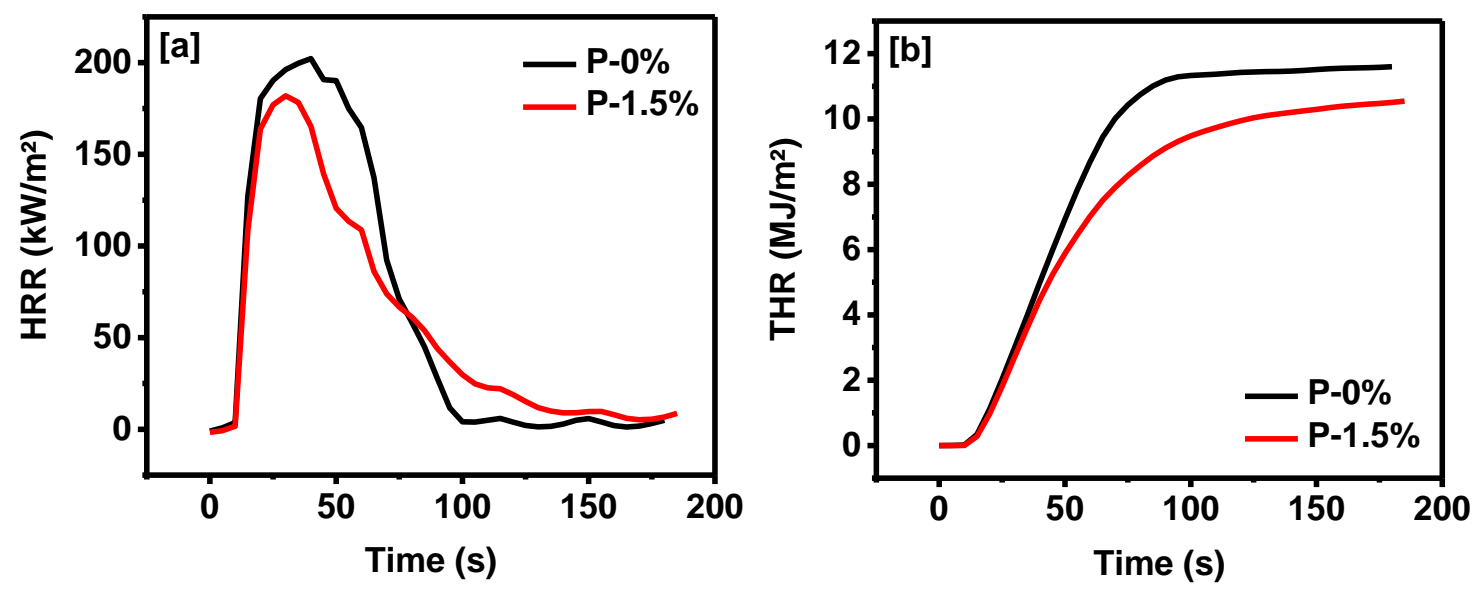

Figure 10. (a) Heat release rate and; (b) total heat release versus time for the foams containing $0 \mathrm{wt} . \%$ and $1.5 \mathrm{wt} . \% \mathrm{P}$.

\section{Conclusions}

In the present study, flame-retardant polyurethane foams were synthesized using corn oil-derived polyol and DMMP. The study conclude that high purity polyol can be synthesized using a single-step thiol-ene reaction. The foams prepared using as-synthesized polyol resulted in a uniform cellular structure, higher closed cell content ( $>95 \%)$, moderate compression strength (120-81 kPa), and appropriate density $\left(\sim 35 \mathrm{~kg} / \mathrm{m}^{3}\right)$. The addition of DMMP resulted in improved flame-retardant properties of the foams. It was observed that foams without DMMP showed a higher burning time of $115 \mathrm{~s}$ with weight loss of $38 \%$, while foams containing $1.94 \mathrm{wt} . \% \mathrm{P}$ showed reduced burning time of $3.5 \mathrm{~s}$ and weight loss of $5.5 \mathrm{wt} . \%$. Similar behavior was observed from the cone test, where the foams containing DMMP showed a reduced peak heat release rate and total heat release, thereby improving the flame retardancy of the polyurethane foams.

Author Contributions: R.K.G. conceived the project and designed the experiments. S.R., C.Z., S.B., and B.N. performed the research. All authors reviewed the manuscript and provided their inputs.

Funding: This research was funded by the Kansas Corn Commission, grant number (1913).

Acknowledgments: This work was supported by a grant from the Kansas Corn Commission at the Pittsburg State University, Pittsburg, Kansas. Ram K. Gupta also expresses his sincere acknowledgment to the Polymer Chemistry Program and Kansas Polymer Research Center, Pittsburg State University, for financial and research support.

Conflicts of Interest: The authors declare no conflict of interest.

\section{References}

1. Zhang, C.; Li, Y.; Chen, R.; Kessler, M.R. Polyurethanes from Solvent-Free Vegetable Oil-Based Polyols. ACS Sustain. Chem. Eng. 2014, 2, 2465-2476. [CrossRef]

2. Gaidukova, G.; Ivdre, A.; Fridrihsone, A.; Verovkins, A.; Cabulis, U.; Gaidukovs, S. Polyurethane rigid foams obtained from polyols containing bio-based and recycled components and functional additives. Ind. Crops Prod. 2017, 102, 133-143. [CrossRef]

3. Zhang, C.; Madbouly, S.A.; Kessler, M.R. Biobased polyurethanes prepared from different vegetable oils. ACS Appl. Mater. Interfaces 2015, 7, 1226-1233. [CrossRef] [PubMed]

4. Elbers, N.; Ranaweera, C.K.; Ionescu, M.; Wan, X.; Kahol, P.K.; Gupta, R.K. Synthesis of Novel Biobased Polyol via Thiol-Ene Chemistry for Rigid Polyurethane Foams. J. Renew. Mater. 2017, 5, 74-83. [CrossRef]

5. Ding, H.; Huang, K.; Li, S.; Xu, L.; Xia, J.; Li, M. Synthesis of a novel phosphorus and nitrogen-containing bio-based polyol and its application in flame retardant polyurethane foam. J. Anal. Appl. Pyrolysis. 2017, 128, 102-113. [CrossRef]

6. Bhoyate, S.; Ionescu, M.; Radojcic, D.; Kahol, P.K.; Chen, J.; Mishra, S.R.; Gupta, R.K. Highly flame-retardant bio-based polyurethanes using novel reactive polyols. J. Appl. Polym. Sci. 2018, 135, 46027. [CrossRef] 
7. Zhang, C.; Bhoyate, S.; Ionescu, M.; Kahol, P.K.; Gupta, R.K. Highly flame retardant and bio-based rigid polyurethane foams derived from orange peel oil. Polym. Eng. Sci. 2018, 58, 2078-2087. [CrossRef]

8. Bhoyate, S.; Ionescu, M.; Kahol, P.K.; Chen, J.; Mishra, S.R.; Gupta, R.K. Highly flame-retardant polyurethane foam based on reactive phosphorus polyol and limonene-based polyol. J. Appl. Polym. Sci. 2018, 135, 46224. [CrossRef]

9. Bhoyate, S.; Ionescu, M.; Kahol, P.K.; Gupta, R.K. Sustainable flame-retardant polyurethanes using renewable resources. Ind. Crops Prod. 2018, 123, 480-488. [CrossRef]

10. Ranaweera, C.K.; Ionescu, M.; Bilic, N.; Wan, X.; Kahol, P.K.; Gupta, R.K. Biobased Polyols Using Thiol-Ene Chemistry for Rigid Polyurethane Foams with Enhanced Flame-Retardant Properties. J. Renew. Mater. 2017, 5, 1-12. [CrossRef]

11. Lu, Y.; Larock, R.C. Soybean-oil-based waterborne polyurethane dispersions: Effects of polyol functionality and hard segment content on properties. Biomacromolecules 2008, 9, 3332-3340. [CrossRef]

12. de Espinosa, L.M.; Meier, M.A. Plant oils: The perfect renewable resource for polymer science?! Eur. Polym. J. 2011, 47, 837-852. [CrossRef]

13. Economic Research Service (ERS). Workbook: World Agricultural Supply and Demand Estimates at a Glance; United States Department of Agriculture (USDA): Washington, DC, USA, 2019.

14. Ash, M.; Knisley, S. Oil Crops Outlook; OCS-16-H; United States Department of Agriculture (USDA): Washington, DC, USA, 2016.

15. Kirpluks, M.; Cabulis, U.; Avots, A. Flammability of Bio-Based Rigid Polyurethane Foam as Sustainable Thermal Insulation Material. In Insulation Materials in Context of Sustainability; IntechOpen: London, UK, 2016.

16. Desroches, M.; Caillol, S.; Lapinte, V.; Auvergne, R.; Boutevin, B. Synthesis of Biobased Polyols by Thiol-Ene Coupling from Vegetable Oils. Macromolecules 2011, 44, 2489-2500. [CrossRef]

17. Konig, A.; Fehrenbacher, U.; Hirth, T.; Kroke, E. Flexible Polyurethane Foam with the Flame-retardant Melamine. J. Cell. Plast. 2008, 44, 469-480. [CrossRef]

18. Feng, F.; Qian, L. The flame retardant behaviors and synergistic effect of expandable graphite and dimethyl methylphosphonate in rigid polyurethane foams. Polym. Compos. 2014, 35, 301-309. [CrossRef]

19. Thirumal, M.; Khastgir, D.; Nando, G.B.; Naik, Y.P.; Singha, N.K. Halogen-free flame retardant PUF: Effect of melamine compounds on mechanical, thermal and flame retardant properties. Polym. Degrad. Stab. 2010, 95, 1138-1145. [CrossRef]

20. Zhao, Q.; Chen, C.; Fan, R.; Yuan, Y.; Xing, Y.; Ma, X. Halogen-free flame-retardant rigid polyurethane foam with a nitrogen-phosphorus flame retardant. J. Fire Sci. 2017, 35, 99-117. [CrossRef]

21. Bhoyate, S.; Ionescu, M.; Kahol, P.K.; Gupta, R.K. Castor-oil derived nonhalogenated reactive flame-retardant-based polyurethane foams with significant reduced heat release rate. J. Appl. Polym. Sci. 2019, 136, 47276. [CrossRef]

22. Tohka, A.; Zevenhoven, R. Processing Wastes and Waste-Derived Fuels Containing Brominated Flame Retardants; Helsinki University of Technology: Espoo, Finland, 2002.

23. Chen, M.J.; Shao, Z.B.; Wang, X.L.; Chen, L.; Wang, Y.Z. Halogen-free flame-retardant flexible polyurethane foam with a novel nitrogen-phosphorus flame retardant. Ind. Eng. Chem. Res. 2012, 51, 9769-9776. [CrossRef]

24. Ionescu, M. Chemistry and Technology of Polyols for Polyurethanes; Rapra Technology: Shrewsbury, UK, 2007.

25. Coates, J. Interpretation of Infrared Spectra A Practical Approach. In Encyclopedia of Analytical Chemistry: Applications, Theory and Instrumentation; John Wiley \& Sons, Ltd.: Hoboken, NJ, USA, 2006.

26. Shea, J.J. Polymeric foams: Mechanisms and materials. IEEE Electr. Insul. Mag. 2005, 21, 56. [CrossRef]

27. Zhang, L.; Zhang, M.; Zhou, Y.; Hu, L. The study of mechanical behavior and flame retardancy of castor oil phosphate-based rigid polyurethane foam composites containing expanded graphite and triethyl phosphate. Polym. Degrad. Stab. 2013, 98, 2784-2794. [CrossRef]

28. Liu, W.; Tang, Y.; Li, F.; Ge, X.G.; Zhang, Z.J. TG-FTIR characterization of flame retardant polyurethane foams materials. IOP Conf. Ser. Mater. Sci. Eng. 2016, 137, 012033. [CrossRef]

29. Xi, W.; Qian, L.; Huang, Z.; Cao, Y.; Li, L. Continuous flame-retardant actions of two phosphate esters with expandable graphite in rigid polyurethane foams. Polym. Degrad. Stab. 2016, 130, 97-102. [CrossRef]

30. Hejna, A.; Kirpluks, M.; Kosmela, P.; Cabulis, U.; Haponiuk, J.; Piszczyk, Ł. The influence of crude glycerol and castor oil-based polyol on the structure and performance of rigid polyurethane-polyisocyanurate foams. Ind. Crops Prod. 2017, 95, 113-125. [CrossRef] 
31. Lorenzetti, A.; Modesti, M.; Besco, S.; Hrelja, D.; Donadi, S. Influence of phosphorus valency on thermal behaviour of flame retarded polyurethane foams. Polym. Degrad. Stab. 2011, 96, 1455-1461. [CrossRef]

32. Laoutid, F.; Bonnaud, L.; Alexandre, M.; Lopez-Cuesta, J.M.; Dubois, P. New prospects in flame retardant polymer materials: From fundamentals to nanocomposites. Mater. Sci. Eng. R Rep. 2009, 63, 100-125. [CrossRef]

33. Pettigrew, A. Halogenated Flame Retardants. In Kirk-Othmer encyclopedia of chemical technology, 4th ed.; John Wiley \& Sons: New York, NY, USA, 1993; Volume 10, pp. 954-976.

34. Pan, H.; Wang, W.; Pan, Y.; Song, L.; Hu, Y.; Liew, K.M. Formation of layer-by-layer assembled titanate nanotubes filled coating on flexible polyurethane foam with improved flame retardant and smoke suppression properties. ACS Appl. Mater. Interfaces 2015, 7, 101-111. [CrossRef]

35. Chen, Y.; Jia, Z.; Luo, Y.; Jia, D.; Li, B. Environmentally Friendly Flame-Retardant and Its Application in Rigid Polyurethane Foam. Int. J. Polym. Sci. 2014, 2014, 7. [CrossRef]

(C) 2019 by the authors. Licensee MDPI, Basel, Switzerland. This article is an open access article distributed under the terms and conditions of the Creative Commons Attribution (CC BY) license (http:/ / creativecommons.org/licenses/by/4.0/). 